East African Medical Journal Vol. 85 No.10 October 2008

FACTORSAFFECTING CONTINUITY AND SUCCESSOF COMMUNITY-BASED REPRODUCTIVE HEALTHSERVICE PROGRAMME IN RURAL COMMUNITY OF NORTHEAST ETHIOPIA

A. Mekonnen, MD, MPH, Reproductive Health and Perinatal Epidemiology Unit, School of Public Health, Free University of Brussels, Route de Lennik 808, CP-597, B-1070, Brussels, Belgium and Department of Family Health, Amhara National Regional State Health Bureau, P.O. Box 495 Bahrdar, Ethiopia, A. Sophie, MD, PhD, Head (Gynae.), Reproductive Health and Perinatal Epidemiology Unit, School of Public Health, Free University of Brussels, Route de Lennik 808, CP-597, B-1070, Brussels, Belgium, M. Dramaix-Willmet, PhD, Head (Biostat.), Department of Biostatistics, School of Public Health, Free University of Brussels, Route deLennik 808, CP-598, B-1070 Brussels, Belgium and A. Bantayehu, MD, MPH, Co ordinator, Community Based Reproductive Health Unit, Health, Women and Youth affairs Department, Amhara Development Association, P.O. Box 307, Bahrdar, Ethiopia

Request for reprints to: Dr. A. Mekonnen, P. O. Box 21400, Addis Ababa, Ethiopia

\title{
FACTORS AFFECTING CONTINUITY AND SUCCESS OF COMMUNITY-BASED REPRODUCTIVE HEALTH SERVICE PROGRAMME IN RURAL COMMUNITY OF NORTHEAST ETHIOPIA
}

\author{
A. MEKONNEN, A. SOPHIE, M. DRAMAIX-WILLMET and A. BANTAYEHU
}

\begin{abstract}
Objective: To assess opportunities and threats towards the continuity and success of Community based reproductive health service programme in Northeast Ethiopia. Design: Community based comparative cross sectional study.

Setting: Two districts of Amhara region, Ethiopia, classified as strong and weak community based reproductive health programme areas.

Subjects: Seven hundred and ninety two women aged 15-49 years residing in the selected districts of Amhara region. Community based reproductive health workers, programme coordinators and field supervisors were used as informants of qualitative data collection.

Main outcome measure: Current use of modern contraceptive methods.

Results: Strong versus weak programme areas: knowledge about modern contraceptive method (MCM), was $(90 \%$ and $86.8 \%)$, [OR $(95 \% \mathrm{CI})=2.87(1.68,4.91)]$, ever use of MCM $(61.1 \%$ and $29.7 \%)$, [OR $(95 \% \mathrm{CI})=3.71(2.72,5.07)]$ and current use of MCM $(54.8 \%$ versus $19.7 \%)$, [OR $(95 \% \mathrm{CI})=4.95(3.53,6.95)$ ]. Method interruption was significantly higher, $37.6 \%$ in weak than $10.9 \%$ in strongly performing programme area. Causes of defaulting in strong versus weak programme areas were: wanted more pregnancy $(4 \%$ and $39.5 \%)$, fear of contraceptives' side effects $(16 \%$ and $31.6 \%)$ and lack of method of choice $(20 \%$ and $2.6 \%)$. Type of religion, husband approval, awareness of service existence and client satisfaction remained to be the predictors of current use of MCM in multivariate analysis. Qualitative study findings were found coherent with the quantitative results.

Conclusion: Type of religion, husband approval, client satisfaction and awareness of service existence were the predictors of modern contraceptive methods utilisation in the study population.
\end{abstract}

\section{INTRODUCTION}

Among women of reproductive age (15-49 years) in developing countries the burden of reproductive ill-health is far greater than the disease burden from tuberculosis, respiratory infections, motor vehicle injuries, homicide and violence or from war (1-3). Ethiopia being one of the world poorest countries has high and unmet health needs. As it is the case in many other developing countries, the health care in general and reproductive health in particular have suffered from inadequate staffing and allocation of resources (3).

Ethiopia is the third most populated country in Africa, has one of the highest population growth rate, $2.9 \%$, and total fertility rate of 5.9 children per woman. Other health status indicators, such as maternal mortality ratio 871 deaths per 100,000 live births, infant mortality Rate 97 per 1000 live births; under five child mortality rate 166 per 1000, life expectancy 
at birth 50 , primary health service coverage $52 \%$, and family planning coverage only $8.1 \%$, are the worst in the world $(4,5)$. In many developing countries, including Ethiopia, community based distribution (CBO) programme has proved to be cost-effective and an alternative approach besides the traditional institution-based service delivery strategy (6-8). Community based distribution programme has been transformed to community based reproductive health programme (CBRHP) in the last few years after governments ratified the International Conference on Population Development (ICPD) programme of action which calls for a comprehensive and clientcentered view of reproductive health in addition to family planning $(9,10,12,14,15)$.

Between March and April 2004, with an objective of assessing the opportunities and threats towards the continuity and success of community based reproductive health service programme, the current study was carried out in the two districts found in South Wollo administrative zone of Amhara region, Ethiopia where the community based reproductive health programme is being implemented by an indigenous and non-governmental community based organisation called Amhara Development Association (ADA) since January 2000.

\section{MATERIALS AND METHODS}

Study design: The study used both quantitative and qualitative study methods. Community based comparative cross sectional study was conducted comparing strong and weak community based reproductive health service programme areas.

Study area: South Wollo Zone is one of the 11 administrative zones in Amhara region, Ethiopia. It is subdivided into 18 districts and again sub divided into 519 kebeles (smallest administrative units). In the current study, Jamma and Sayint districts were taken as weak and strong performing $\mathrm{CBRH}$ programme areas respectively (11). Jamma district is 110 and Sayint 207 kilometres away from the capital of the zone, Dessie town. Both districts have agrarian economy. However, Jamma district is relatively surplus producing area as compared to Sayint that is mainly characterised by poor infrastructure, drought prone, poor land fertility and rugged landscape. Based on the presence of the smallest health unit, the physical health service coverage of Jamma and Sayint districts is $48 \%$ and $50 \%$ respectively.

Study population: The study population included women in the reproductive age group (15-49 years), residing in the geographic boundaries of Jamma and Sayint districts of Amhara region, Ethiopia.

\section{Selection criteria (Empirical)}

Strong CBRI-IP areas: These are districts with a contraceptive prevalence rate (CPR) of $15 \%$ or more and $\%$ of active CBRH agents above $90 \%$.

Weak CBRHP areas: These are districts with a contraceptive prevalence rate of $4 \%$ and $\%$ of active CBRH agents $<50 \%$.

Sampling procedure and sample size determination: Multistage sampling techniques have been employed. Among eleven zones in Amhara region, South Wollo zone was selected due to the presence of the $\mathrm{CBRH}$ programme. During the data collection period, twelve districts were implementing $\mathrm{CBRH}$ programme in the Zone. Based on pre-defined empirical criteria stated above, these twelve districts were classified into two as strong and weakly implementing community based reproductive health service programme areas, out of each group the extreme (either the strongest or the weakest) was selected and included in the study. Out of the rural villages found in each selected district, a total of eight villages (four from each district)were randomly selected and included in the study. Finally, households were systematically identified. The number of households included in the study was determined using proportional allocation method based on the population size of each village. In each household, a woman in the reproductive age group was enrolled in the study and interviewed. If there was more than one eligible woman in a household, one was selected by lottery method. In case there was non-eligible in the selected household the next household was included in the study. Using EPl6 statcalc for two proportions, 792 women in the reproductive age (15-49 years) group were included in the study.

Variables in the study: Independent variables included socio-demographic characteristics such as age, educational level, religion, marital status and past reproductive characteristics: number of pregnancies, number of children and history of unwanted pregnancies. Knowledge, attitude, practice towards modern contraceptive methods and knowledge, perceptions, approaches and views of women with regard to community based reproductive health service were also considered. Current use of modern contraceptive method was the outcome variable in this study.

Data collection and analysis: Quantitative data was collected in a house-to-house interview based on structured questionnaire. The questionnaire was translated intolocal language, pre-tested and refined before the actual data collection was launched. Data 
collectors were secondary school graduates, with previous experience in data collection techniques, and trained for three days. Two staff nurses were recruited and trained to be supervisors and facilitators of qualitative data collection.

Qualitative data were collected through individual in-depth interview with responsible programme coordinators, supervisors and health workers at different level and focus group discussion with women and CBRH agents. Each focus group was composed of eight to ten people. Semi structured open-ended questionnaire guide was used to collect information. Quantitative data were entered with EPI info version 6.04 and analysed using statistical package for social sciences (SPSS) version 11.5. Odds ratio and chi square test were used to asses statistical association, whereas $95 \%$ confidence interval and $\mathrm{p}$-value for statistical significance. Where chi square test was not appropriate, Fisher's exact test was used. Logistic regression analysis was also performed to see the relative effect of the predictors on the dependant variable.

\section{RESULTS}

Quantitative part: A total of 792 women in reproductive age group (15-49 years) were interviewed, out of which 397 and 395 were in the strong and weak CBRH programme areas respectively. Baseline characteristics of these populations are presented in Table 1 (distribution of socio-demographic characteristics) and Table 2 (past reproductive history of women).

The mean \pm S.D ages in the strong and weak areas were $28.9 \pm 7.8$ and $27.6 \pm 8.4$ respectively. Three hundred and forty two $(86.4 \%)$ and $339(85.8 \%)$ of the women in strong and weak programme areas respectively were currently married. In the strong and weak programme areas respectively, three hundred and eighty nine (98\%) and $280(70.9 \%)$ were orthodox Christians while four (1\%) and 111 (28.1\%) were Muslims. Among respondents, 66.2\% of the strongly performing and $63.7 \%$ of the weak programme areas respectively cannot read and write. Threehundred and thirty five (84.8\%) and $320(81.6 \%)$ in strong and weakly performing areas respectively were housewives.

Table 1

Socio-demographic characteristic of strongly and weakly performing CBRHP areas, South Wollo, Ethiopia, April 2004

\begin{tabular}{|c|c|c|c|c|c|c|}
\hline \multirow[b]{2}{*}{ Variable } & \multicolumn{2}{|c|}{$\begin{array}{l}\text { Strongly performing } \\
\text { CBRHP areas }(n=397)\end{array}$} & \multicolumn{2}{|c|}{$\begin{array}{l}\text { Weak CBRHP } \\
\text { areas }(n=395)\end{array}$} & \multirow[b]{2}{*}{$\mathrm{X}^{2}$} & \multirow[b]{2}{*}{ P-value } \\
\hline & No. & $(\%)$ & No. & $(\%)$ & & \\
\hline \multicolumn{7}{|l|}{ Age (years) } \\
\hline $15-19$ & 54 & 13.6 & 51 & 12.9 & 10.50 & 0.062 \\
\hline $20-24$ & 55 & 13.9 & 77 & 19.5 & & \\
\hline $25-29$ & 92 & 23.2 & 96 & 24.3 & & \\
\hline $30-34$ & 81 & 20.4 & 56 & 14.2 & & \\
\hline $35-39$ & 64 & 16.1 & 53 & 13.4 & & \\
\hline$\geq 40$ & 51 & 12.8 & 62 & 15.7 & & \\
\hline Mean \pm SD & 28.9 & \pm 7.8 & 27.6 & \pm 8.4 & & \\
\hline \multicolumn{7}{|l|}{ Marital Status } \\
\hline Married & 342 & 86.4 & 339 & 85.8 & 0.68 & 0.878 \\
\hline Divorced & 27 & 6.8 & 27 & 6.8 & & \\
\hline Widowed & 8 & 2 & 6 & 1.5 & & \\
\hline Single & 19 & 4.8 & 23 & 5.8 & & \\
\hline \multicolumn{7}{|l|}{ Religion } \\
\hline Orthodox & 389 & 98 & 280 & 70.9 & 140.9 & $0.000^{*}$ \\
\hline Muslim & 4 & 1 & 111 & 28.1 & & \\
\hline Others & 4 & 1 & 4 & 1 & & \\
\hline \multicolumn{7}{|l|}{ Education } \\
\hline Illiterate & 263 & 66.2 & 251 & 63.7 & 0.56 & 0.45 \\
\hline Literate & 134 & 33.8 & 143 & 36.3 & & \\
\hline \multicolumn{7}{|l|}{ Occupation } \\
\hline Farmer & 34 & 8.6 & 33 & 8.4 & 5.34 & 0.254 \\
\hline Housewives & 335 & 84.8 & 320 & 81.6 & & \\
\hline Local drink sellers & 6 & 1.5 & 15 & 3.8 & & \\
\hline Students & 11 & 2.8 & 10 & 2.6 & & \\
\hline Others & 9 & 1.3 & 14 & 3.6 & & \\
\hline
\end{tabular}

NB: * Fischer exact test 
The median numbers of pregnancies and currently alive children a woman had in both programme areas were found to be four and three respectively. Unwanted pregnancy was reported by $14(4 \%)$ and $19(5.4 \%)$ of women in the strong and weak programme areas respectively. History of spontaneous abortion was reported $22.4 \%$ vs. $19.7 \%$ in the strong and weakly performing CBRH programme areas. No women except two, in the weak areas reported history of induced abortion.

Statistical analysis for these baseline characteristics showed that the populations did not differ, except in terms of religion, showing a greater amount of women with Orthodox Christianity in the strong intervention area.

Knowledge, Attitude and Practice (KAP) towards modern contraceptive methods: The knowledge of modern contraceptive methods (MCM) was $95 \%$ in the strong, and $86.8 \%$ in the weakly performing CBRHP areas with statistically significant difference $[\mathrm{OR}(95 \% \mathrm{CI})=$ $2.87(1.68,4.91)]$. Ever use of $\mathrm{MCM}, 61.1 \%$ in the strong and $29.7 \%$ in the weak CBRHP areas, was statistically significant $[\mathrm{OR}(95 \% \mathrm{CI})=3.71(2.72,5.07)]$. Though statistically significant difference was not observed, among never users, $50 \%$ and $59 \%$ of the respondents had future plan to use CBRH service in the strong and weak programme areas respectively [OR $(95 \%$ CI $)$ $=0.69(0.36,1.32)]$. Current use of MCM was $54.8 \%$ of women in strong and 19.7\% in the weak CBRHP areas was also statistically significant $[\mathrm{OR}(95 \% \mathrm{CI})=$ $4.95(3.53,6.95)]$. No difference was observed between current users, $72.5 \%$ and $80 \%$ that used injectable form and, OCP $26.4 \%$ and $16.9 \%$ in the strong and weak CBRH programme areas respectively. One hundred and eighty six $(93.9 \%)$ and $56(94.9 \%)$ of the current users in the strong and weak programme areas respectively, were using the method of their choice. Among ever users, contraceptive supply problems were encountered in $42(18.3 \%)$ and $17(16.8$ $\%$ ) of women in strong and weak areas respectively (Table 3). Among current users, husband's approval was found to be $95.2 \%$ versus $96.5 \%$ in the strong and weak programme areas with no statistically significant difference, $[(\mathrm{c} 2=0.18, \mathrm{P}=0.67)]$.

Table 2

Past reproductive characteristic history of women in the Community based reproductive health programme areas of South W 0110 Zone, April 2004

\begin{tabular}{|c|c|c|c|c|c|c|}
\hline Variable & \multicolumn{2}{|c|}{$\begin{array}{l}\text { Strongly performing } \\
\text { CBRHP areas } \\
\text { No. } \quad(\%)\end{array}$} & \multicolumn{2}{|c|}{$\begin{array}{c}\text { Weak CBRHP } \\
\text { areas }\end{array}$} & $X^{2}$ & P-value \\
\hline Total number of pregnancies & \multicolumn{2}{|c|}{$(\mathrm{n}=397)$} & \multicolumn{2}{|c|}{$(\mathrm{n}=395)$} & \multirow{7}{*}{0.72} & \multirow{7}{*}{0.95} \\
\hline 0 & & 9.8 & 40 & 10.1 & & \\
\hline $1-3$ & 142 & 35.9 & 146 & 37.0 & & \\
\hline 4-6 & 131 & 33.1 & 133 & 33.7 & & \\
\hline $7-9$ & 73 & 18.4 & 64 & 16.2 & & \\
\hline$\geq 10$ & 11 & 2.8 & 12 & 3 & & \\
\hline Median & 4.0 & & 4.0 & & & \\
\hline \multicolumn{6}{|l|}{ Alive number of } & \multirow{6}{*}{0.79} \\
\hline 0 & 5 & 1.4 & 4 & 1.1 & \multirow[t]{4}{*}{1.04} & \\
\hline $1-3$ & 176 & 49.6 & 184 & 52.3 & & \\
\hline $4-6$ & 136 & 38.3 & 123 & 34.9 & & \\
\hline $7-10$ & 38 & 10.7 & 41 & 11.6 & & \\
\hline Median & \multirow{2}{*}{\multicolumn{2}{|c|}{$\begin{array}{l}3.0 \\
(\mathrm{n}=354)\end{array}$}} & \multirow{2}{*}{\multicolumn{2}{|c|}{$\begin{array}{l}3.0 \\
(\mathrm{n}=354)\end{array}$}} & & \\
\hline History of unwanted pregnancy & & & & & & \multirow{4}{*}{0.37} \\
\hline Yes & 14 & 4 & 19 & 5.4 & \multirow[t]{3}{*}{0.79} & \\
\hline No & 340 & 96 & 335 & 94.6 & & \\
\hline History of spontaneous abortion & \multicolumn{2}{|c|}{$(n=353)$} & \multicolumn{2}{|c|}{$(\mathrm{n}=305)$} & & \\
\hline Yes & 79 & 22.4 & 58 & 19.7 & \multirow[t]{3}{*}{3.35} & \multirow[t]{3}{*}{0.19} \\
\hline No & 274 & 77.6 & 247 & 80.3 & & \\
\hline History of induced abortion & \multicolumn{2}{|c|}{$(\mathrm{n}=317)$} & \multicolumn{2}{|c|}{$(\mathrm{n}=266)$} & & \\
\hline Yes & - & & 2 & 0.8 & \multirow[t]{2}{*}{2.39} & \multirow[t]{2}{*}{$0.21 *$} \\
\hline No & 317 & 100 & 264 & 99.2 & & \\
\hline
\end{tabular}

Note: * Fischer exact test, ${ }^{1}$ Those women who had at least one pregnancy 
Table 3

Comparison of knowledge, attitude and practice of modem contraceptive methods between strong and weak CBRHP areas, South Wollo, April 2004

\begin{tabular}{|c|c|c|c|c|}
\hline Variable & $\begin{array}{c}\text { Strong CBRHP } \\
\text { areas } \\
\text { No. } \quad(\%)\end{array}$ & $\begin{array}{c}\text { Weak CBRHP } \\
\text { areas } \\
\text { No. } \quad(\%)\end{array}$ & OR & $(95 \%$ CI $)$ \\
\hline Knowledge of MCM & $(n=397)$ & $(\mathrm{n}=395)$ & & \\
\hline Yes & $377 \quad 95$ & $341 \quad 86.8$ & 2.87 & $(1.68,4.91)$ \\
\hline No & 20 & 13.2 & $1^{*}$ & \\
\hline Future plan to use CBRHS & $(n=1461)$ & $(\mathrm{n}=2391)$ & & \\
\hline Yes & 25 & 59 & 0.69 & $(0.36,1.32)$ \\
\hline No & 50 & 64 & & \\
\hline Ever use ofMCM & $(\mathrm{n}=397)$ & $(\mathrm{n}=395)$ & & \\
\hline Ever used & $229 \quad 61.1$ & $101 \quad 29.7$ & 3.71 & $(2.72,5.07)$ \\
\hline Never used & 38.9 & 70.3 & $1^{*}$ & \\
\hline Current use of MCM & $(n=397)$ & $(\mathrm{n}=395)$ & & \\
\hline Users & $204 \quad 54.8$ & 19.7 & 4.95 & $(3.53,6.95)$ \\
\hline Non users & $168 \quad 45.2$ & 80.3 & $1^{*}$ & \\
\hline Use of Method of choice & $(\mathrm{n}=2042)$ & $(\mathrm{n}=652)$ & & \\
\hline Yes & $186 \quad 93.9$ & $56 \quad 94.9$ & 0.83 & $(0.23,3.05)$ \\
\hline No & 6.1 & 5.1 & & $1^{*}$ \\
\hline MCM supply problems & $(\mathrm{n}=2294)$ & $(\mathrm{n}=1014)$ & & \\
\hline Faced & $42 \quad 18.3$ & 16.8 & 1.11 & $(0.59,2.06)$ \\
\hline Not faced & $187 \quad 81.7$ & 83.2 & $1^{*}$ & \\
\hline MCM used by current users & $(\mathrm{n}=2043)$ & $(\mathrm{n}=653)$ & & \\
\hline Injection & $148 \quad 72.5$ & $52 \quad 80.0$ & 0.58 & $(0.26,1.25)$ \\
\hline Tablet & 26.4 & 16.9 & $1^{*}$ & \\
\hline Others & 10.49 & 1.5 & & \\
\hline
\end{tabular}

Note: * reference values, ${ }^{1}$ Never users rfMCMs, ${ }^{2,3}$ Current users of $\mathrm{MCM}$, ${ }^{4}$ Ever Users of MCM

Causes of interruption and never use of MCM as reported by women: Eleven percent of women in strongly performing programme area had interrupted the use of MCM as compared to $37.6 \%$ ) in the weak programme area that is statistically significant at $[\mathrm{OR}(95 \% \mathrm{CI})=4.92(2.66,9.15)]$. The major reasons for method interruption in strong versus weak programme areas respectively were: need for more pregnancies, $4 \%$ vs. $39.5 \%$, fear of untoward effects of contraceptives, $16 \%$ vs. $31.6 \%$ and absence of method of one's choice $20 \%$ vs. $2.6 \%$. The three most frequent reasons for never use were: need for more children $58.2 \%$ vs. $59.8 \%$, lack of information $11 \%$ vs. $11.3 \%$ and absence of sexual partner $14.4 \%$ vs. $5.9 \%$ in the strong and weak programme areas respectively (Figure 1). No statistically significant difference was observed for reasons of method interruption and never use between the two populations except that higher proportion of womenin strong performing area responded the need for more pregnancies as a reason for method interruption, (c2 = 12.21, $\mathrm{P}=0.00)$.

Knowledge, perception and views of women towards CBRH services:Significantly higher proportion, $92.4 \%$ in strong than $67.4 \%$ in weak $\mathrm{CBRH}$ programme areas, know the existence of $\mathrm{CBRH}$ agents in their village $[\mathrm{OR}(95 \% \mathrm{CI})=5.88(3.83,9.02)]$ (Table 4). There was a trend towards a greater involvement of women in the recruitment process of CBRH agents. "Ever talked with village CBRH agent" between the strong $81.9 \%$ and weak areas, $72.6 \%$ respectively, was statistically significant [OR $(95 \% \mathrm{CI})=1.7 \mathrm{I}(1.16,2.49)]$. Among women who had ever-talked, $264(74.7 \%)$ and $180(69.7 \%)$ in strong and weak programme areas respectively received at least one type of RH service. Peer pressure so as to be a client of CBRH service was exerted by $112(29.8 \%$ ) of women in strong programme area as compared to $45(12.7 \%$ ) in the weak programme area. The difference was statistically significant, [OR $(95 \% \mathrm{CI})=2.92(1.99,4.29)]$ (TabIe-4). More than $80 \%$ of the women in both programme areas responded that the one-time fee for service ( 0.50 Birr for a cycle of OCP and 3 Birr for an injection of depo-provera, equivalent to 0.06 and 0.35 USD respectively) was neither expensive nor constitutes a barrier to their family income. The perception of respondents that many other people were using $\mathrm{CBRH}$ service in their village was significantly higher, $69.6 \%$ in strong, 
than $38.3 \%$ in weak programme areas, [OR $(95 \% \mathrm{CI})$ $=3.69(2.71,5.01)]$. Though more than $85 \%$ of women in both programme areas reported high level of service satisfaction, statistically significant higher proportion was observed among women in strong programme areas $[\mathrm{OR}(95 \% \mathrm{CI})=3.07(1.64,5.75)]$.

Figure 1

Comparison of reasons for interpretation and never use of MCM in the strong and weak programme areas

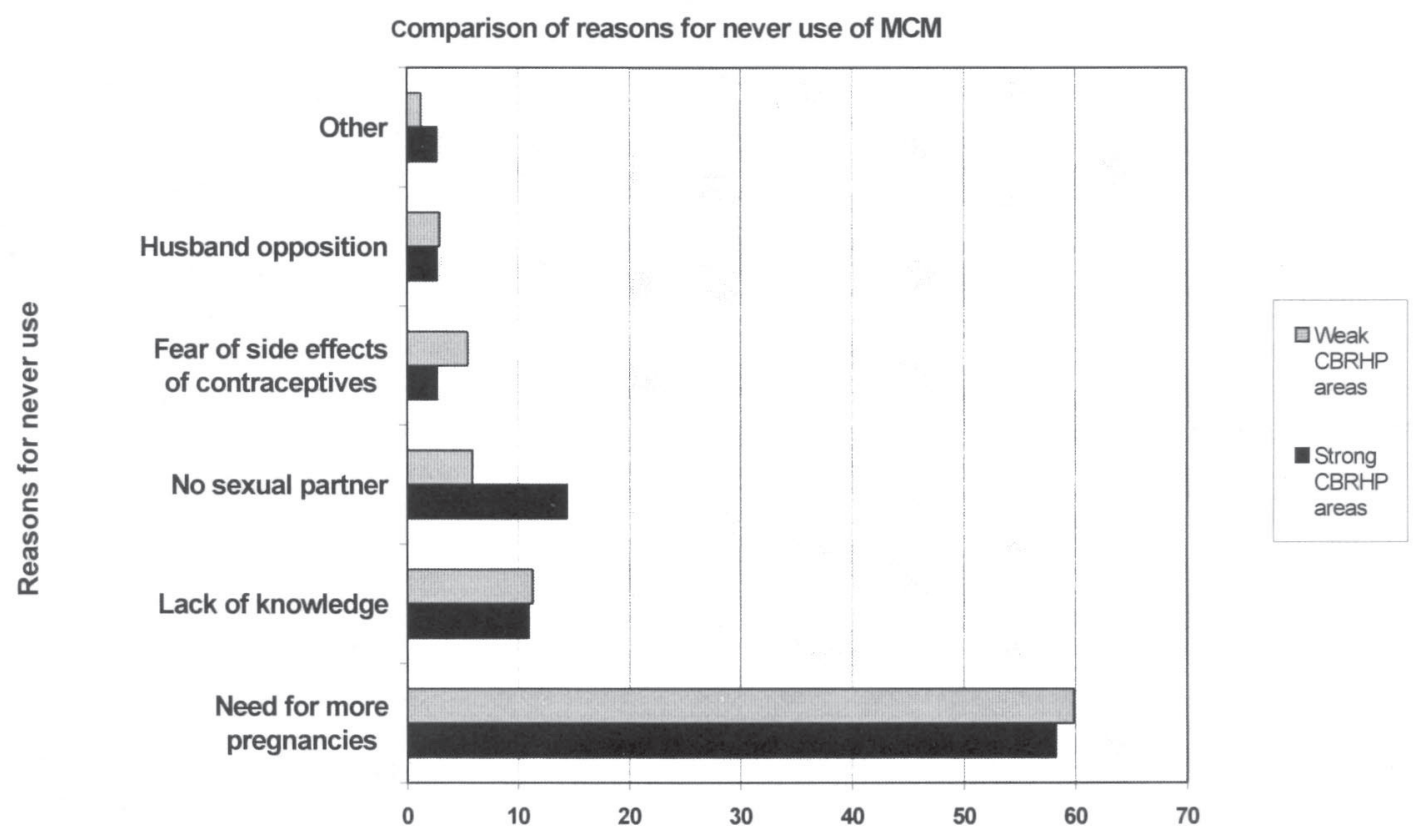

Percent, reasons for never use

Comparison of reasons for interruption of MCM between strong and weak programme areas

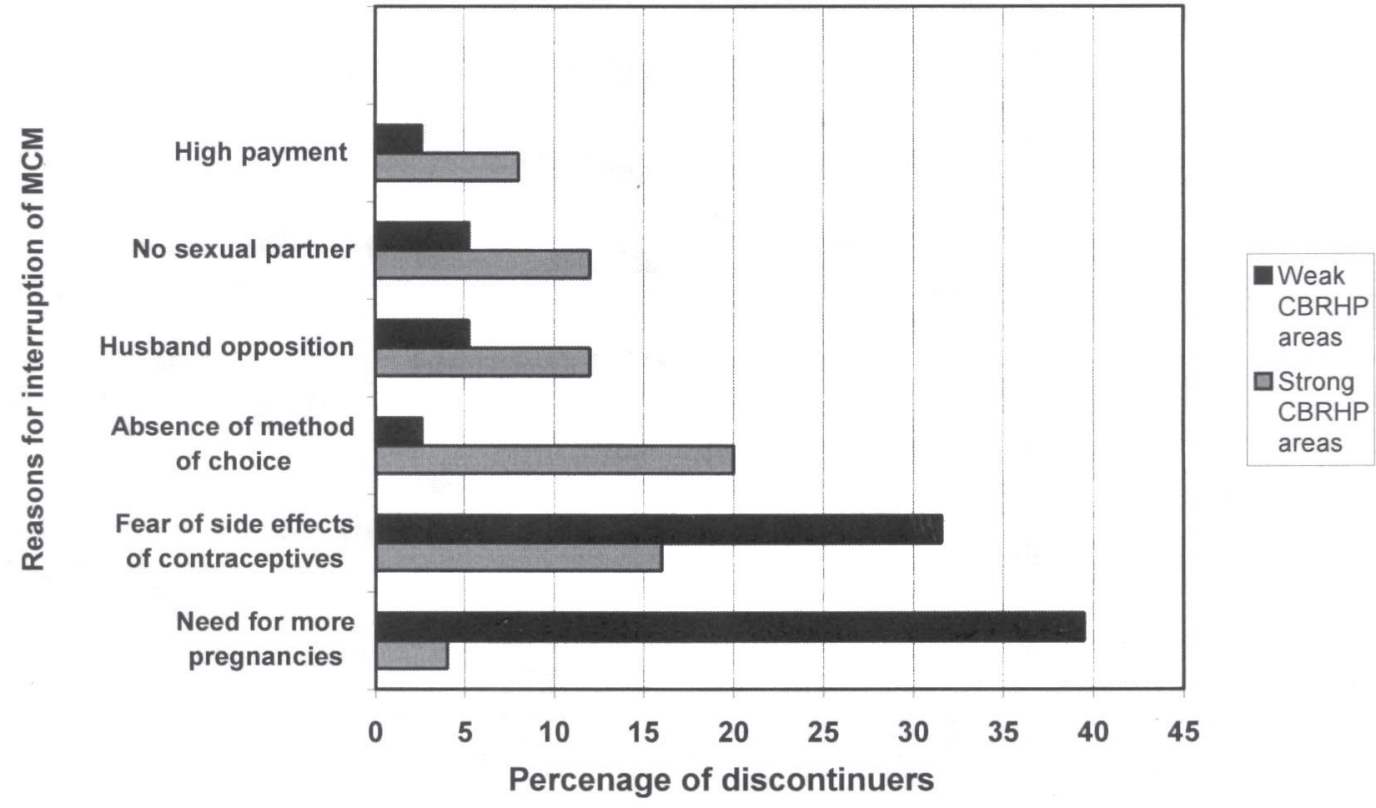


The odds of discontinuing the service contraceptive method in use, if the current project based CBRH programme came to an end or phased out was three times higher in strongly performing areas, $82.7 \%$ compared to, $60.1 \%$, in weak programme area $[\mathrm{OR}(95 \% \mathrm{CI})=3.17(1.95,514)]$.

Socio-demographic andother pertinent variables in relation to current use of MCM: Socio-demographic variables, such as age, occupation, number of currently alive children, level of education and opinion of women to the affordability of the fee for service showed no statistically significant association with current use of MCM. It was found that, being currently married was associated with the use of one form of modern contraceptive method as compared to others (single, divorced and widowed) [OR $(95 \% \mathrm{CI})=1.64(1.01$, 2.66)].

To be Christian (Orthodox) in religion was significantly associated with current use of modern contraceptive methods as compared to Muslim [OR $(95 \% \mathrm{CI})=3.12(1.82,533)[$. The odds of using MCM were six times higher among women whosehusbands approve family planning than those who do not [OR $(95 \% \mathrm{CI})=5.79(2.94,11.41)]$. Awareness of women to the existence of CBRH agents in their village $(98.1 \%)$ and level of satisfaction by the service received from CBRH agents $(97 \%)$ were significantly associated with current use of MCM [OR $(95 \% \mathrm{CI})=15.22(6.11$, $37.95)$, and $3.39(1.49,7.66)$ respectively] (Table 5).

Table 4

Comparison of perceptions, approaches and views of women towards CBRHS in strong and weak CBRH programme areas of South Wollo, Ethiopia, April 2002

\begin{tabular}{lcccc}
\hline Variable & Weak CBRHP & & \\
areas $(\mathrm{n}=397)$ & areas $(\mathrm{n}=395)$ & & \\
No. $(\%)$ & No. $(\%)$ & OR & $(95 \%$ CI $)$
\end{tabular}

Awareness of women to the existence of CBRHA in one's village

Yes

Involvement of women

in the recruitment of

CBR" agents
Yes

$$
\text { No }
$$

Ever talked with the

CBRH agents

$$
\text { Yes }
$$$$
\text { No }
$$

Ever received advice and and service on $\mathrm{RH}$ from the CBRHA

$$
\begin{aligned}
& \text { Yes } \\
& \text { No }
\end{aligned}
$$

Ever influence a friend or neighbour to use $\mathrm{CBRH}$ service

$\begin{array}{cccccc}\text { Yes } & 112 & 29.8 & 45 & 12.7 & 2.92 \\ \text { No } & 264 & 70.2 & 310 & 87.3 & 1^{*}\end{array}$

$\begin{array}{ccc}265 & 67.4 & 5.88 \\ 128 & 32.6 & 1^{*}\end{array}$

$\begin{array}{rl}365 & 92.4 \\ 30 & 7.6\end{array}$

$\begin{array}{ccccc}\left(\mathrm{n}=365^{\star *}\right) & \left(\mathrm{n}=265^{\star *}\right) & \\ 94 & 26 & 62 & 23.4 & 1.15 \\ 268 & 74 & 203 & 76.6 & 1^{*}\end{array}$

$\begin{array}{lllll}65 & 18.1 & 72 & 27.4 & 1^{*}\end{array}$

$\begin{array}{llc}177 & 69.7 & 1.28 \\ 77 & 30.3 & 1^{*}\end{array}$

$\begin{array}{lllll}91 & 25.3 & 77 & 30.3 & 1^{*}\end{array}$


Continuation of Table 4

Opinion on the one-time

fee for service requested

by CBRH agents

$\begin{array}{lllllll}\text { Affordable/ fair } & 234 & 89 & 219 & 84.9 & 0.69 & (0.42,1.16) \\ \text { Not affordable/expensive } & 29 & 11 & 39 & 15.1 & & \end{array}$

Women perception on

CBRH service use in

their village

\begin{tabular}{|c|c|c|c|c|c|c|}
\hline \multicolumn{7}{|c|}{$\begin{array}{l}\text { Many people are using } 261 \\
\text { Not so many people }\end{array}$} \\
\hline $\begin{array}{l}\text { Not so many people } \\
\text { are using }\end{array}$ & 114 & 30.4 & 219 & 61.7 & & \\
\hline \multicolumn{7}{|l|}{ atisfaction with } \\
\hline \multicolumn{7}{|l|}{ BRH agents } \\
\hline Satisfied & 312 & 95.1 & 203 & 86.4 & 3.07 & $(1.64,5.75)$ \\
\hline Not satisfied & 16 & 4.9 & 32 & 13.6 & & \\
\hline \multicolumn{7}{|l|}{ Nomen intention when } \\
\hline \multicolumn{7}{|l|}{ he current programme } \\
\hline \multicolumn{7}{|l|}{ tops / phase out } \\
\hline Stop the service/method & 172 & 82.7 & 92 & 60.1 & 3.17 & $(1.95,5.14)$ \\
\hline $\begin{array}{l}\text { Continue the service/ } \\
\text { method anyway }\end{array}$ & 36 & 17.3 & 61 & 39.9 & $1^{*}$ & \\
\hline
\end{tabular}

Note: *reference values, ${ }^{* *}$ those who are aware of the existence of CBRH agent in their village.

Table 5

Socio-demographic and other pertaining variables in relation to current use of modern contraceptive methods, South Wollo, Ethiopia, April 2004

\begin{tabular}{|c|c|c|c|c|c|}
\hline Variable & Yes & $\begin{array}{l}\text { Current use of } \\
(n=269)\end{array}$ & $\begin{array}{l}\mathrm{MCM} \\
\text { No }(n=433)\end{array}$ & OR & $(95 \%$ CI $)$ \\
\hline \multicolumn{6}{|l|}{ Age } \\
\hline$\geq 28$ & 154 & $(57.2)$ & $232 \quad(53.6)$ & 1.61 & $(0.85,1.58)$ \\
\hline$<28$ & 115 & $(42.8)$ & $201 \quad(46.4)$ & $1^{*}$ & \\
\hline \multicolumn{6}{|l|}{ Marital Status } \\
\hline Married & & & $242(90.3)$ & $368(85)$ & $1.64(1.01,2.66)$ \\
\hline $\begin{array}{l}\text { Others (single, widowed, } \\
\text { separated) }\end{array}$ & 26 & (9.7) & $65 \quad(15)$ & $1^{*}$ & \\
\hline Occupation & & & & & \\
\hline $\begin{array}{l}\text { House wives } \\
\text { Others (farmers, local }\end{array}$ & 233 & $(86.9)$ & $351 \quad(81.8)$ & 1.48 & $(0.96,2.28)$ \\
\hline $\begin{array}{l}\text { drink sellers, } \\
\text { students)“ }\end{array}$ & 35 & (13.1) & $78 \quad(18.2)$ & $1^{*}$ & \\
\hline \multicolumn{6}{|l|}{ Educational status } \\
\hline Literate & 92 & $(34.2)$ & $163(37.7)$ & 0.84 & $(0.62,1.18)$ \\
\hline Illiterate & 177 & $(65.8)$ & $269 \quad(62.3)$ & $1^{*}$ & \\
\hline
\end{tabular}


Continuation of Table 5

Religion

Christian/Orthodox Muslim

$\begin{aligned} 246 & (93.2) \\ 18 & (6.8)\end{aligned}$

$351 \quad(81.4)$

$80 \quad$ (18.6)

3.12

$1^{*}$

$(1.82,5.33)$

No. of currently alive children

$\begin{array}{llllll}>4 & 99 & (38.4) & 120 & (31.3) & 1.37 \\ \leq 4 & 159 & (61.6) & 263 & (68.7) & 1^{*}\end{array}$

Husband approval to

FP methods
Approve
232 (95.5)
$193 \quad(78.5)$
5.79
Disapprove
11 (4.5)
53 (21.5)
$1^{*}$
$(2.94,11.41)$

Awareness of women's

to the existence of CBRHA

in their village

$\begin{array}{ccccccc}\text { Yes } & 264 & (98.1) & 333 & (77.6) & 15.22 & (6.11,37.95) \\ \text { No } & 5 & (1.9) & 96 & (22.4) & 1^{*} & \end{array}$

Women's opinion to

the one time fee for

service requested by CBRHA

$\begin{array}{lcccccc}\text { Affordable/Fair } & 258 & (97) & 192 & (83.8) & 1.62 & (0.96,2.75) \\ \text { Not affordable/Expensive } & 8 & (3) & 37 & (16.2) & 1^{*} & \end{array}$

Women satisfaction by

the CBRHS

$\begin{array}{lclrlr}\text { Satisfied } & 258 & (97) & 238 & (90.5) & 3.39 \\ \text { Not satisfied } & 8 & (3) & 25 & (9.5) & 1^{*}\end{array}$

Table-6

* Reference values

Results of logistic regression analysis for possible explanatory variables of current use of MCM, South Wollo, Ethiopia, April 2004

Current use of MCM

Variable

Adjusted OR

$(95 \%$ CI $)$

Religion

Christian/Orthodox

3.73

$(1.81,7.68)$

Muslim

$1^{*}$

Awareness to the existence of

CBRHA in their village

Yes

6.28

$(1.20,32.92)$

No

$1^{*}$

Husband approval to FP methods

Approve

Disapprove

$1^{*}$

Women Satisfaction by CBRHS

Satisfied

Not satisfied

$1^{*}$

NS: Marital status *reference values 
Results of logistic regression analysis: By putting those predictors that had significant association with current use of modern contraceptive methods (MCM) in the univariate analysis and avoiding the redundant ones, logistic regression analysis was performed. As a result, Religion remained significantly associated with current use of MCM in regression analysis; those who were Christian! Orthodox were more likely to use MCM than Muslims [AOR $(95 \% \mathrm{CI})=3.73(\mathrm{I} .81$, 7.68)]. Current use of MCM found to have significant association with client satisfaction [AOR $(95 \% \mathrm{CI})$ $=3.08(1.09,8.7 \mathrm{I})]$. Being knowledgeable on the existence of CBRHS were more likely to be MCM user than not $[$ AOR $(95 \%$ CI $)=6.28(1.29,3292)]$ Husband approval remained as a predictor of Modern contraceptive use in the logistic model [AOR (95\% $\mathrm{CI})=4.33(2.03,9.25)]($ Table 6$)$.

Qualitative part: The qualitative part was aimed at getting better understanding of the situation, surveying potential users, field workers and programme managers.

Focus group discussion with women aged 15-49 years: A total of four focus group discussions sessions, two in each district, consists of thirty-three women, (16 in weak and 17 in strong programme areas) were conducted. All participants were illiterate, currently married and had a range of two to eleven children.

The objective of the focus groups was to explore and document additional and / or new information that was not captured by the quantitative method. Majority of the participants in both study areas knew injection form (depo-provera) and oral contraceptive method (OCP). Half of the respondents mentioned condom as MCM and two women mentioned rhythm method. Most of the women had heard of the existence of the CBRH service in their village from the $\mathrm{CBRH}$ workers that conducted a door-to-door visit to inform them about reproductive health issues. All except a woman, were not using and even some of them knew nothing at all, about FP prior to the introduction of the CBRH programme in their villages. All women unanimously agreed that they started using MCM after thorough discussion and approval by their husbands. Participants in both study areas agreed that they were using the method of their first choice. Injectable form was mainly chosen as compared to OCP in both study areas. The large majority of the CBRH service users in both study areas had a great concern and worry to the sustainability of the programme.

Focus group discussion with community based reproductive health workers: Two sessions, one in each study area, consists of a total of eighteen, 13 males and five females, CBRH agents, were conducted.
All discussants were currently married and had a range of two to six children. All respondents in both study areas were willing and happy at the time of recruitment as CBRH worker, now and on wards. However, they considered that the two weeks family planning focused pre-service training they got was not enough to provide them with the necessary knowledge to respond to the challenging questions that came from their clients. As to fee for the service, all of them unanimously agreed that the fee for service they were retaining from users was not better than nothing as compared to the range of services they were expected to render.

Among the further challenges/problems mentioned by CBRH agents in both study areas, lack of uniformity in the payment pattern between government health institutions and the $\mathrm{CBRH}$ programme was the most frequent response. This discrepancy, according to them, created a sense of untruthfulness and dishonesty on their work.

CBRH workers were asked whether or not they themselves were using MCM. Out of eight FGO participants in the strongly performing CBRHP areas, six of them were using MCM since the beginning of the programme, one was widowed and the other argued the use of rhythm method. On the other hand in the weak CBRHP areas, out of ten participants, four were using MCM where as six of them were not due to bad health condition, strong belief that they were naturally spacing their birth and one of them claimed to use rhythm method.

Individual in-depth interview with programme cocoordinators and field supervisors: Interviewees pointed out that CBRH service had largely and meaningfully contributed to the existing health care service delivery, especially in the creation of access to basic RH service to the underserved community, acting as a bridge between the conventional health care system and the community and improved contraceptive prevalence rate (CPR) in the area. In the view of programme coordinators, the success and sustainability of the programme depends on the continuous supply of contraceptive commodities, re-evaluation of the ever volunteerism of CBRH agents, reducing the work load of each agent, current CBRHA-client ratio (1:700 households), and participation and commitment from the local leaders. Interviewees also agreed that steps moved as to the sustainability of the programme so far were not satisfactory. Currently, users' fee collected from each client would be transferred to the zonal common pot so that zone manages the fee collected to buy contraceptive commodities. However, there is an intention, in the near future, to handover this responsibility of fee management and provision of FP commodities to the district social committee and district health office. 


\section{DISCUSSION}

As expected, differences in the Community Based Reproductive Health service utilisation pattern have been observed between the strong and weak programme areas. The use of both quantitative and qualitative study methods, comparative approach and the inclusion of inaccessible and underserved study areas were the strengths of this study. The scientific sampling procedures and the use of appropriate statistical tests to rule out chances, bias and confounding effect helped to improve the validity of the study. However, the design of the study, being cross sectional, also shares its inability to establish an antecedent-consequence relationship of events. Though vital characteristics were compared between the strong and weak programme areas, there could be potential source of bias / confounders due to the complexity and interlinked nature of some factors.

Many of the findings in our study are similar to earlier observations. Population characteristics differed only in terms of religion, with a predominantly Christian population in the strong as compared to the weak programme area. In the current study, women in the strong programme area which is predominantly Orthodox Christian had shown a better use of reproductive health services. Studies done in relation to community based distribution and family planning in Ethiopia have shown mixed results in that some programmes were successful even in the predominantly Muslim communities (8). In another community based study in Northern Ethiopia, though both Orthodox Christianity and Islam religions play a role in influencing the use of contraception, $53 \%$ of women had responded that they would take contraceptives irrespective of the words of religious leaders (7). The fertility and family planning survey of 1996-97 in Pakistan, where more than $97 \%$ of the population is Muslim, showed that, among women who were currently married and never users of contraceptives, $10 \%$ offered religion as the main reason for never use (24).

The prevalence of unwanted pregnancy was found much lower in both programme areas than other studies. In addition to the problem of underreporting, it is generally considered that rural people use children as an additional source of labour force to the family, which might partly explain our results.

A statistically significantdifference was observed in the knowledge of women towards MCM (at least one method) between the strong and weak programme areas. The result of the knowledge of women in the strong programme area was higher than in similar studies in the Eastern part of Ethiopia, $89.1 \%$, Tigray $89 \%$, Northern Ethiopia $84.6 \%$ and a national figure of $82 \%(5,7)$.
More than fifty percent of never users in both programme areas had future intention to use $\mathrm{CBRH}$ service. This positive attitude could be viewed as one of the potential grounds to the initiation of similar programmes in the future. Unlike similar studies in Ethiopia, and as compared to the national figure, where OCP is the predominant family planning method used (13,17-19), current users in this study were using injection form of contraception followed by OCP. Focus group discussions with current MCM users and CBRH agents in both study areas had also confirmed this finding. Consideration of continuous supply of injectable form of contraception, to comply with the method of choice, could improve the perceived quality of CBRH programme $(17,19)$. The need for more children and fear of side effects of contraceptives were the most frequent reasons of method interruption among women in the weak programme area. In the strong programme area, husband opposition was reported as well as absence of choice of method. This could show that there was a lack in designing of education and counselling strategy in the weak programmearea on the one hand and unmet needs in the strong programme area on the other hand.

Current MCM users in both programme areas, with no statistical difference, reported that their husbands were aware and approved the method that they were using. During focus group discussion sessions, women also unanimously agreed that husband approval was an important step to use MCM. Controlling other socio-demographic variables, husband approval had also remained to be a significant predictor of current use of MCM in the logistic regression model. Experiences from Eastern Turkey, Bangladesh, Ghana and Indonesia also showed, among women who desire to have no more children, the major cause for non use of methods was attributed to husband's disapproval $(7,16,20-23)$.

The difference in the awareness of women to the existence of $\mathrm{CBRH}$ agents in their village between the two programme areas was statistically significant. Taking current use of MCM as an outcome variable, aw areness of the existence of $\mathrm{CBRH}$ workers remained significant in the multivariate analysis. This knowledge of women could serve as an entry point in the initiation of interpersonal communication with CBRH workers.

Though peer pressure has been demonstrated in adolescent health literatures to be an important factor (27), not much has as yet been done in Ethiopia on this topic which maybe an important point, as the currentstudy demonstrated that a significantly higher proportion of women in the strong programme area had ever influenced their friends or neighbours to use CBRHservices. This peer pressure effect could serve as an entry point to approach non-users in the future. 
Despite the concern of CBRH workers on the scantiness of the fee retained from a client, women in both programme areas had the opinion that the one time fee for service set for the service was fair and affordable. Experiences from Indonesia had shown that a trend of women seeking fee based family planning programmes was at its increase in the mid 1990 's $(25,26)$. Non-uniformity in the payment pattern between CBRH services and government health institutions was an issue of discussion during focus group discussion sessions. CBRH workers had also a concern that this discrepancy created them a sense of dishonesty and unreliability.

Unlike that of the fee-for service scheme of CBRH programme, the nearby public health facilities in both study areas run routine Reproductive health service without charge. Prospects for the women after the ongoing programme stops or phases out were found alarming. Only one fifth and forty percent of the current users in the strong and weak programme areas respectively responded that they would continue the methods they were using in any possible way. Unless it is intervened at its outset, this tendency could be a potential threat to the programme success and continuity. Though programme coordinators were keen and moving a step forward to get rid of the threats of the programme, meaningful effort was not exerted towards system establishment at the grass root level especially in the coordination and initiation of the fee management by the local people.

The following three areas were identified as topics that need further exploration: the difference in attitude and tradition towards the practice of contraception as a function of religious identity, the discrepancy between the opinion of client and service providers on the affordability of the one time fee-for service and policy consideration of fee for RH service in the government healthinstitutions to sustain $\mathrm{CBRH}$ programme.

\section{CONCLUSION}

Though the programme was designed in the same manner, and, CBRH agents were willing to do theirjob well in both programme areas, it was demonstrated that for some reasons, that could be external factors (opportunities and threats), they were unable to put forward their message in the weak areas. Strategic approach to certain community groups such as husbands of non-users and religious opposition groups could make a difference towards the success of the $\mathrm{CBRH}$ programme. The motivation of the $\mathrm{CBRH}$ agents, the currently fair and demand based supply of contraceptive commodities, the intersectoral collaboration between actors and the positive attitude of clients towards the CBRH agents were seen as opportunities in the strong programme areas. On the contrary, the poorly designed reproductive health education strategy, the lack of commitment and absence of shared vision among stakeholders, as it was demonstrated in the weak programme areas, werelooked as potential threat to the programme. The great concern and worry of clients on their prospect when the current donor motivated and project based programme halts needs an urgent attention.

\section{ACKNOWLEDGEMENT}

This study was partially financed by Amhara development association, community based reproductive health project, Bahrdar Ethiopia.

\section{REFERENCES}

1. World Health Organisation. The Global burden of reproductiveill health. Progress in Human Reproduction Research. 1997; 42:1-8.

2. Turmen, T. Operationalizing Reproductive Health: The Mother-Baby Package. Geneva, World Health Organisation. 1995;

3. World Health Organization. Evidence based reproductive health in developing countries. Reprod. Health Library. 1999; 2: 1-2.

4. Ministry of Health. Health and Health related indicators. Addis Ababar; Ethiopia. 1999.

5. CentralStatistical Authority. Ethiopia, Demographic and Health survey. Addis Ababa, Ethiopia. 2000.

6. UNAIDS/WHO. 2000. Epidemiological fact sheet and sexually transmitted infections. (2000 update).

7. Getnet, M. CBD of FP as perceived by people in the reproductive age group, N. and S. Gondar Zones, Ethiopia. Ethiopian J. Health Dev. 2000; 14: 31-42.

8. Kora, A. Community-based family planning survey: A performance assessment of the Jimma family planning CBD project. Ethiopian J. Health Dev. 1997; 11: 17-22.

9. From rhetoric to reality. Delivering reproductive health promises through integrated services. wwww. fhi.orglenlwsplwspubslrehtor.html

10. Lush, L. et al. integrating reproductive health: myth and ideology. Bull. WHO. 1999; 77: 771-777.

11. ANRS health Bureau. 2000. Annual Health Activity report. (1999/2000).

12. Gordon, G. and Phiri, F. Moving beyond the 'KAP GAP': A community based reproductive health programme in eastern province, Zambia. Int. Institute Environ. Dev. 2000;

13. Argaw, D., Fantahun, M. and Berhane, Y. Factors affecting sustainability and success of community based reproductive health programmes in rural Northwest Ethiopia. Proceedings of the 13th Annual conference of the Ethiopian PublicHealth Association, Addis Ababa, 2002; Abstract 39.

14. Sahlu, H., Guernyd.J. and Stloukal, L. Provision of reproductive health services in sub-Saharan Africa. Lessons, issues, challenges and the overlooked rural majority. Population programme service, FAO women and population division. Posted January 2000.

15. FHD, MOH. Curriculum for the training of CBRHA, Ethiopia. 1997. 
16. Terefe, A. and Larson, C. P. Modern contraception use in Ethiopia: Does involving husbands make a difference? Am. J. Public Health. 1993; 83: 1567-1571.

17. Pariani, S., Heer, D,M. and Van Arsdol, M.D. Does choice make a difference to contraceptive use? Evidence from east Java. Stud. Fam. Plann. 1991; 22: 384-390.

18. Chen, S. and Guilkey, D.K. Determinants of contraceptive method choice in rural Tanzania between 1991 and 1999. Stud. Fam. Plann. 2003; 34: 263-276.

19. Magadi,M.A. and Curtis,S.L.Trends and determinants of contraceptive choice in Kenya. Stud. Fam. Plann. 2003; 34: 149-159.

20. Sahin, H.A. and Sahin, H.G. Reasons for not using family planning methods in Eastem Turkey. Eur. J. Contracept. Reprod. Health Care. 2003; 8: 11-16.

21. Kamal, N. Theinfluence of husbands on contraceptive use by Bangladesh women. Health Policy Plan. 2000; 15: $43-51$.
22. Ezch A.C. The influence of spouses over each other's contraceptive attitudes in Ghana. Stud. Fam. Plann. 1993; 24: 163-174.

23. Joesoef, M.R., Baughman, A.L., and Utomo, B. Husband's approval of contraceptive use in metropolitan Indonesia: Programme implications. Stud. Fam. Plann. 1998; 19: 162-168.

24. Ali, M. and Ushisima, H. Perceptions of men on role of religious leaders in reproductive health issues in rural Pakistani. Bio Soc. Sci. 2005; 37: 115-122.

25. Taniguchi, H. Willing to pay for FP service in Indonesia. Integration. 1993:2-3.

26. Williams, C.H. Client satisfaction. Integration. 1993; 38: 14-17.

27. Erulkar, Annabel, S., Mekbib, T., Simie, N. and Gulema, T. Differential use of adolescent reproductive health programmes in Addis Ababa, Ethiopia. J. Adolescent Health. 2006; 38: 253-260. 